\title{
A toolkit for transgenesis at the ROSA26 locus by
}

\section{recombinase-mediated cassette exchange [version 1; peer}

\section{review: 1 approved with reservations, 2 not approved]}

\author{
Kristina Williams ${ }^{1}$, Xiaoyun Zhao ${ }^{2}$, Wallace S Chick² \\ ${ }^{1}$ Department of Pediatrics, University of Colorado Denver, Aurora CO, 80045, USA \\ 2Deparment of Cell and Developmental Biology, University of Colorado Denver, Aurora CO, 80045, USA
}

V1 First published: 29 Jul 2013, 2:162

https://doi.org/10.12688/f1000research.2-162.v1

Latest published: $29 \mathrm{Jul} 2013,2: 162$

https://doi.org/10.12688/f1000research.2-162.v1

\section{Abstract}

We describe a toolkit to perform transgenesis at the ROSA26 locus by recombinase-mediated cassette exchange that will eliminate the inherent problem of random insertion via traditional pronuclear injection. A recombination site-tagged embryonic stem (ES) cell line and two cloning vectors were constructed to facilitate the generation of targeted ES cells with the transgene of interest at ROSA26. The experimental procedure is simple and efficient, and can be readily adapted in many laboratories for rapid generation of transgenic mice.

\section{Keywords}

Recombinase mediated cassette exchange; RMCE; ROSA26; ES cells; Knock in; transgenic mouse; gene targeting; GFP

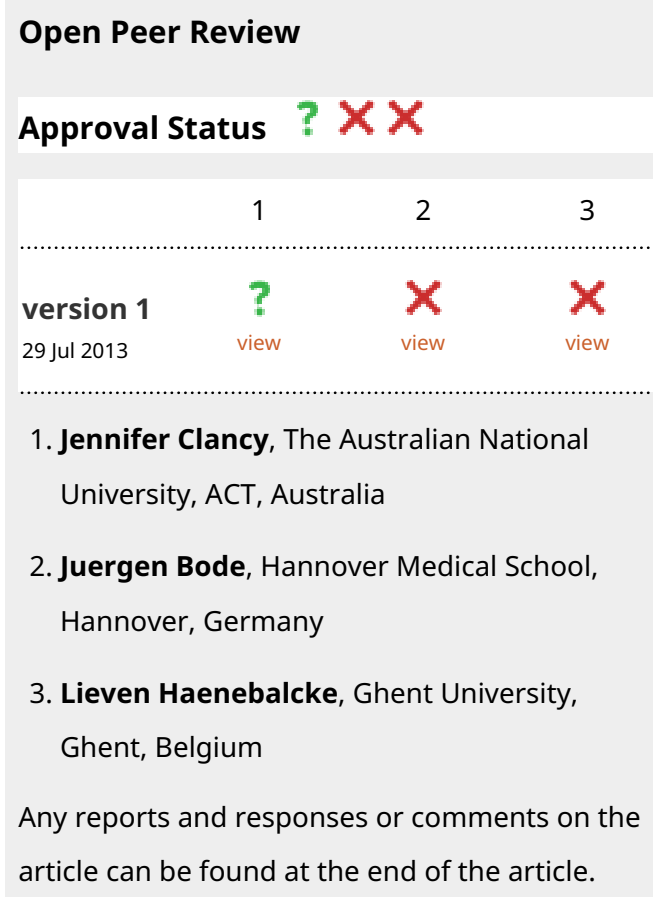

1. Jennifer Clancy, The Australian National University, ACT, Australia

2. Juergen Bode, Hannover Medical School, Hannover, Germany

3. Lieven Haenebalcke, Ghent University, Ghent, Belgium Any reports and responses or comments on the article can be found at the end of the article.

Corresponding author: Wallace S Chick (Wallace.Chick@ucdenver.edu)

Competing interests: No competing interests were disclosed.

Grant information: This work is supported by the National institute of Health (NIH), Rocky Mountain Neurological Disorders core grant P30 NS048154. This paper is subject to the NIH Public Access Policy.

The funders had no role in study design, data collection and analysis, decision to publish, or preparation of the manuscript.

Copyright: ( 2013 Williams K et al. This is an open access article distributed under the terms of the Creative Commons Attribution License, which permits unrestricted use, distribution, and reproduction in any medium, provided the original work is properly cited. Data associated with the article are available under the terms of the Creative Commons Zero "No rights reserved" data waiver (CC0 1.0 Public domain dedication).

How to cite this article: Williams K, Zhao X and Chick WS. A toolkit for transgenesis at the ROSA26 locus by recombinase-mediated cassette exchange [version 1; peer review: 1 approved with reservations, 2 not approved] F1000Research 2013, 2:162 https://doi.org/10.12688/f1000research.2-162.v1

First published: 29 Jul 2013, 2:162 https://doi.org/10.12688/f1000research.2-162.v1 


\section{Introduction}

Transgenic mice created by pronuclear injection of a transgene have been a valuable resource for studying gene effects in a whole animal context, albeit there are several pitfalls of this technique. A well-known drawback was the randomness of transgene insertion where an endogenous gene or important regulatory element might be disrupted, resulting in a phenotype independent of the transgene of interest. Usually, multiple founders had to be tested and characterized before a clean transgenic mouse line could be established. To circumvent the inherent defect of this type of passive transgenesis, several approaches have been developed ${ }^{1}$ that allow transgenes to be inserted at defined genomic loci, such as ROSA26. These active forms of transgenesis can be achieved by utilizing a site-specific recombination system ${ }^{2}$ to facilitate the knock-in of the gene of interest. We have developed a toolkit (a ROSA26-tagged mouse embryonic stem (ES) cell line and two exchange vectors) for efficient gene knock-in at the ROSA26 locus in mouse ES cells by recombinase-mediated cassette exchange (RMCE). Standard microinjection of the knock-in ES cells would subsequently produce a chimera and the knock-in mice expressing the gene of interest, constitutively or conditionally, depending on which exchange vector is used.

\section{Method}

First, we generated a mouse ES cell line, designated as R26FNF31F1 (1F1), in which the ROSA26 allele was targeted with a FRT and F3 flanked phosphoglycerate kinase (PGK) promoter and neomycin (Neo) selection cassette by homologous recombination in EC7.1 ES cells (Figure 1A), a hybrid strain with a background of $\mathrm{C} 57 \mathrm{BL} / 6$ and $129 \mathrm{X} 1 / \mathrm{SvJ}^{3}$. A targeting construct was made by

A

Wildtype
ROSA 26 allele

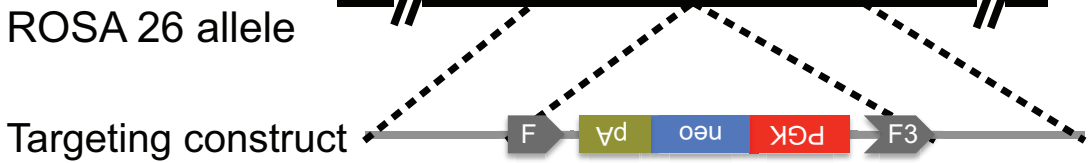

Homologous recombination

ROSA26

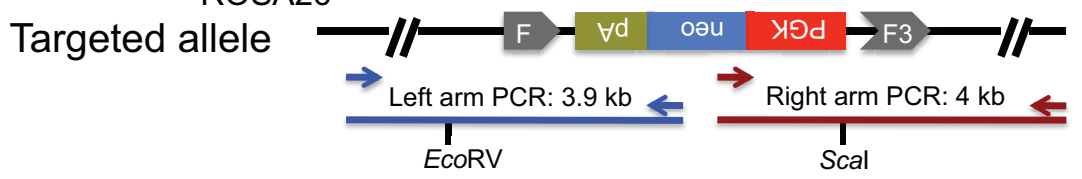

Left arm PCR Right arm PCR

$L$ EcoRV R Scal

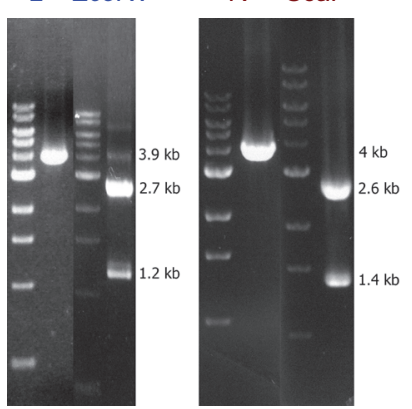

B
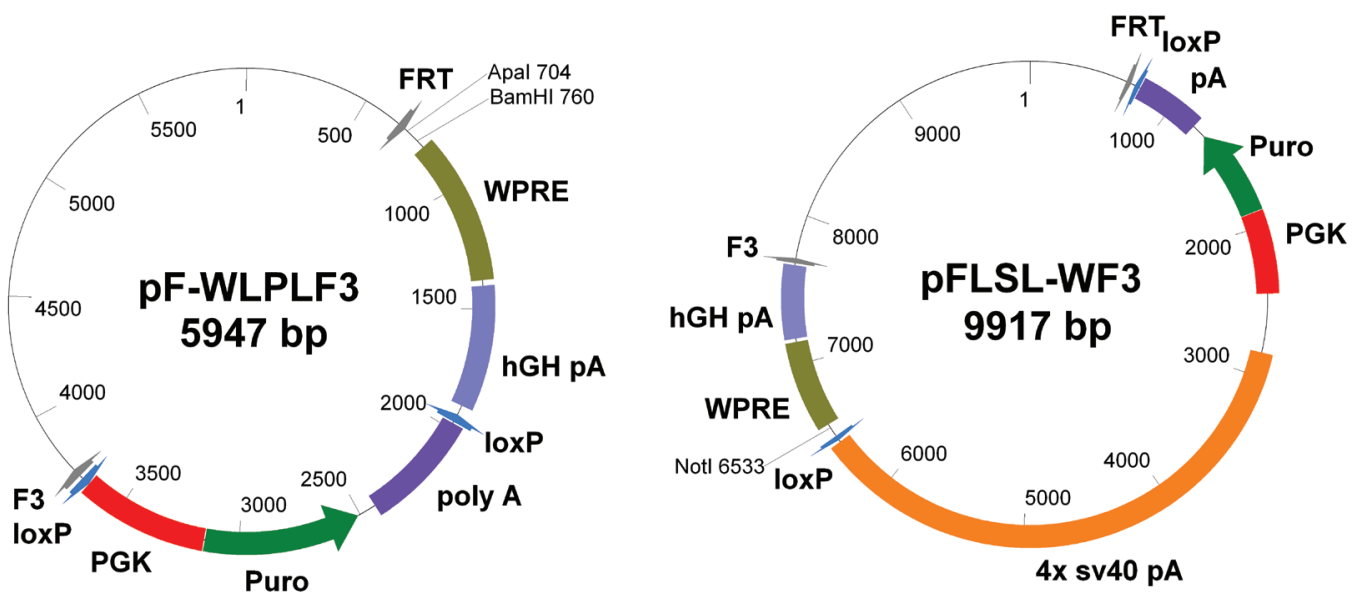

Figure 1. Reagents for recombinase-mediated cassette exchange (RMCE) at the ROSA26 locus. (A) Targeting the ROSA26 allele. The ROSA26 allele was targeted with a FRT and F3 flanked PGK promoter and neomycin selection cassette by homologous recombination in EC7.1 embryonic stem (ES) cells. Clones were screened for the homologous recombination event by long-range PCR. The PCR products were digested with specific enzymes (EcoRV for the left arm and Scal for the right arm) to confirm the identities. (B) Cloning vectors for the generation of the recombination cassette. pF-WLPLF3: a transgene could be cloned at the Apal or BamHI site in a way that the downstream WPRE-pA will allow proper transcription. The floxed PGK-puro selection marker could be removed from the targeted allele after recombination if so desired. pFLSL-WF3: a transgene could be cloned at the Notl site which is downstream of a floxed-STOP sequence (a tandem array of four SV40 polyA signals). The transgene will express once the STOP sequence is deleted by Cre-recombinase. 
the subcloning of a $5.8 \mathrm{~kb} \mathrm{BamHI}$ fragment from the BAC clone RP23-401D9; a FRT-PGK-neo-F3 cassette amplified from PL451 (a gift from NCI Frederick) was inserted into the $\mathrm{XbaI}$ site so that the left and right homologous arms were both $2.9 \mathrm{~kb}$ in length. The PGK-neo marker was cloned in an opposite direction with respect to the ROSA26 locus. EC7.1 ES cells $\left(5 \times 10^{6}\right)^{3}$ were electroporated with $20 \mu \mathrm{g}$ of linearized targeting construct and a total of 192 clones were screened for the homologous recombination event by long-range PCR. The PCR products were digested with specific enzymes (EcoRV for the left arm and ScaI for the right arm) to confirm the identities. A total of 7 targeted clones were recovered; clone R26FNF3-1F1 was established and was used in the subsequent experiments.

To facilitate the cloning of the transgene, we made two exchange vectors; one for constitutive expression ( $\mathrm{pF}$-WLPLF3), and another for conditional expression, mediated by the cre/loxP system (pFLSL-WF3) (Figure 1B). A woodchuck hepatitis post-transcriptional regulatory element (WPRE) was also incorporated to enhance transgene expression. Both vectors have the recombination sites FRT and F3 flanking the transgene cassette, and in the case of pFLSL-WF3, a floxed-STOP cassette was inserted upstream of the transgene to prevent expression until a cre-mediated deletion of the STOP cassette had taken place, allowing spatial and temporal control of expression ${ }^{4,5}$.

The 1F1 ES cells were cultured with primary mouse embryonic fibroblasts (PMEF) (Millipore, Billerica, MA) as feeders in KnockOut DMEM (Life Technologies, Carlsbad, CA) supplemented with 15\% FBS (Tissue Culture Biologicals, Los Alamitos, CA) 1,000 U/ ml LIF (ESGRO) (Millipore, Billerica, MA), $100 \mu \mathrm{M}$ non-essential amino acids (Life Technologies, Carlsbad, CA), 2 mM GlutaMAX (Life Technologies, Carlsbad, CA), $55 \mu \mathrm{M}$ 2-mercaptoethanol (Life Technologies, Carlsbad, CA), and $25 \mathrm{U}$ Pen/Strep (Life Technologies, Carlsbad, $\mathrm{CA}$ ), at $37^{\circ} \mathrm{C}$ and $5 \% \mathrm{CO}_{2}$. They were passaged one-tenth when confluent, typically every two days. To illustrate the efficiency of RMCE in knocking-in and expressing a green fluorescent protein (GFP) marker, we transfected $5 \times 10^{6} 1 \mathrm{~F} 1 \mathrm{ES}$ cells by electroporation with $15 \mu \mathrm{g}$ of pF-GFP-WLPLF3 and $15 \mu \mathrm{g}$ of pCAG-Flpe $^{6}$ (Addgene plasmid 13787). Electroporation was carried out in a $4 \mathrm{~mm}$ cuvette on the Gene Pulser Xcell (Bio-Rad, Hercules, $\mathrm{CA})$ at 250 volts and $500 \mu \mathrm{F}$ capacitance. The transformants were plated onto three $100 \mathrm{~mm}$ dishes containing DR4 mouse fibroblasts as feeders (Applied Stem Cell, Menlo Park, CA); puromycin (1 $\mu \mathrm{g} /$ ml) (Sigma-Aldrich, St. Louis, MO) was applied $24 \mathrm{hr}$ post-plating. Resistant clones were allowed to grow for seven days after which a total of 96 individual colonies were hand picked, trypsinized, and cultured in a 96-well plate. We made replica plates when the colonies were confluent so that one set of cells was cryo-preserved in $10 \%$ DMSO (Sigma-Aldrich, St. Louis, MO) at $-80^{\circ} \mathrm{C}$, one set was subjected to a G418 (250 $\mu \mathrm{g} / \mathrm{ml})$ (Life Technologies, Carlsbad, CA) sensitivity test, and another set of cells was lysed to isolate genomic
DNA for genotyping analysis 7 . From the 96 clones tested, we found 8 clones that were G418 sensitive (Figure 2B), indicating loss of the original neo cassette, through the exchange of the transgene cassette (Figure 2A). The clones that were puromycin resistant but still retained G418 resistance should be clones that had random integration of the transgene cassette without displacing the neo cassette at the ROSA26 locus. The exchange was further confirmed by PCR analysis (Figure 2C). Briefly, a pair of primers annealing to the upstream sequence of the ROSA26 locus and the GFP (arrows indicated in Figure 2A) were employed to amplify the cassette exchange product. We then analyzed GFP expression of the knock-in as well as a randomly picked background clone (Puro ${ }^{R} \mathrm{G} 418^{\mathrm{R}}$ ). By using fluorescent microscopy on a Axiovert 200M microscope (Zeiss, Jena, Germany) on live ES cells, we confirmed two of the selected knockin clones (B7 and B12) exhibited GFP expression while the background clone D5 did not (Figure 2D), suggesting that the knock-in GFP marker at the ROSA26 locus was functionally expressed.

\section{Summary}

In summary, we present here a protocol and the associated reagents required for a very efficient gene knock-in at the ROSA26 locus in mouse ES cells using recombinase-mediated cassette exchange. Two cloning vectors are described for the generation of a transgene exchange cassette in a single cloning step. The timeline from transfection of ES cells to the isolation of recombinant clones is approximately two to three weeks. We observed that the recombination rate of RMCE was quite high so that recombinants could be isolated easily. For the GFP transgene we observed an $8 \%$ recombination rate. Ninety-six clones of two other RMCE transgenesis (Pik3r1 and NpHR-eYFP) generated by the same approach were screened (by PCR and the G418 sensitivity test) as described above, yielding $12 \%$ and $31 \%$ recombination rates, respectively, suggesting that no more than a single 96-well plate of clones need to be harvested and analyzed. Moreover, the screening of recombinants was straightforward and easy to interpret. Unlike gene targeting by homologous recombination, the PCR genotyping for RMCE events in these experiments was very efficient because of the small size of amplicons ( $500 \mathrm{bp})$. As a side note, we observed that PCR was optimal when using DMSO $(2.5 \%)$ and a reduced $\mathrm{Mg}^{2+}$ concentration $(1 \mathrm{mM})$ in the PCR buffer, an observation we encountered whenever we attempted to amplify at the ROSA26 locus. In parallel, the G418 sensitivity test served as confirmatory evidence of gene exchange. Overall, we found that the experimental procedure is simple to perform and exhibits high efficiency. It could easily be adopted by other laboratories. The 1F1 ES cells were derived from a F1 hybrid strain with a background of C57BL/6 and 129X1/SvJ. Our experience with these hybrid ES cells is that they contribute to the germline efficiently, even after a variety of in vitro manipulations ${ }^{3,8}$. The FRT-neo-F3 cassette was targeted to the C57BL/6 allele into which the transgene will be exchanged; mice derived could then be backcrossed to attain a pure C57BL/6 background which, depending on the intended mouse study, might be desirable. 


\section{A Targeted ROSA26 allele of $1 \mathrm{~F} 1 \mathrm{ES}$ cells}
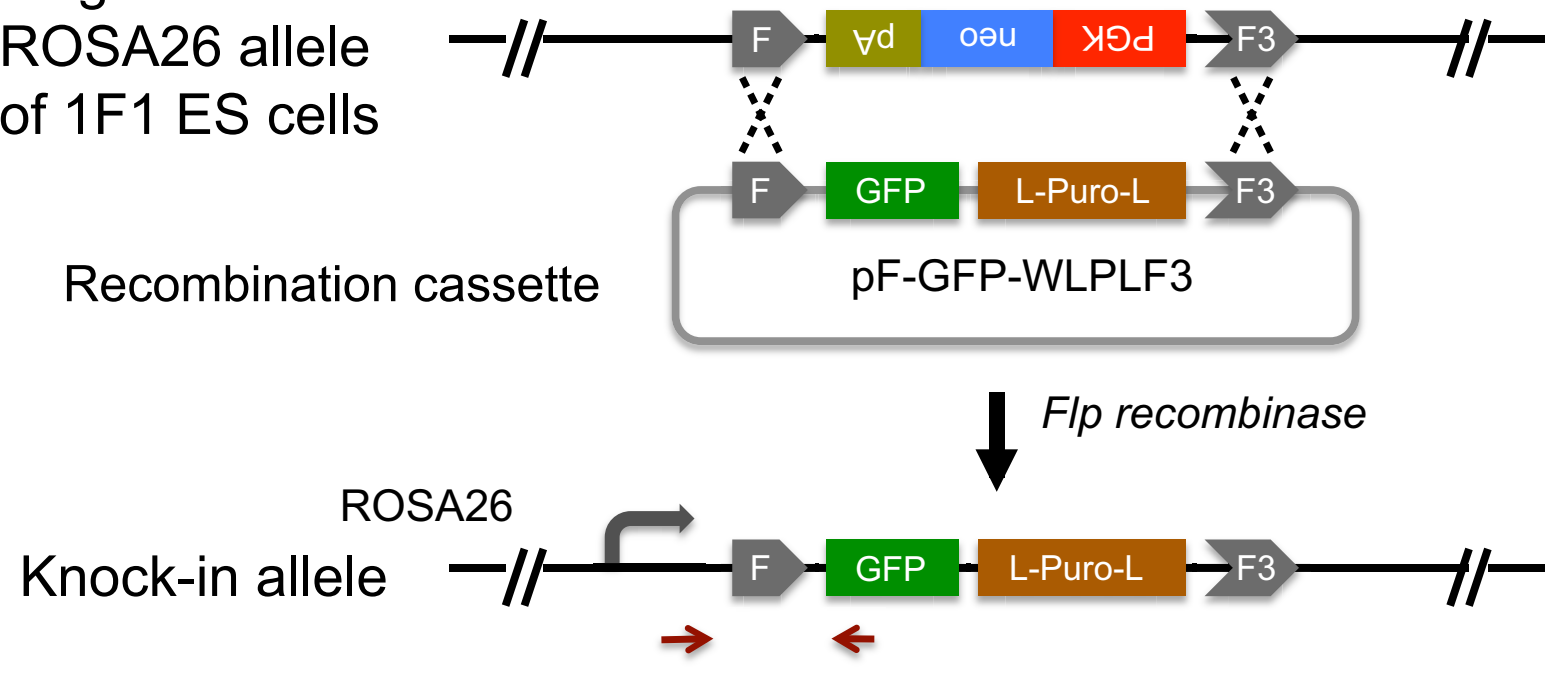

B

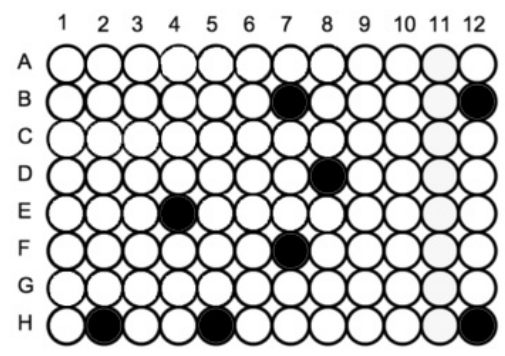

C

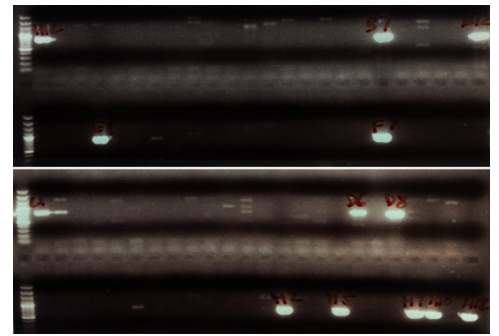

D

Bright field

GFP

Figure 2. Recombinase-mediated cassette exchange (RMCE). (A) Schematic of RMCE. Circular plasmids of the exchange vector pF-GFP-WLPLF3 and the pCAG-Flp expression vector were transfected into 1F1 embryonic stem (ES) cells. Recombinants were selected for puromycin resistance; each individual clone was then seeded onto the well of a 96-well plate. (B) G418 sensitivity test. The black wells represent those ES cell clones that were killed by G418 (PuroR G418 ), indicating the loss of the originally tagged neo marker. (C) Genotyping analysis for the RMCE event. ES cells were analyzed by PCR (the primers are represented by the arrows in Figure 2A) for the correct integration of GFP into the ROSA26 allele. (D) Expression of GFP. Knock-in ES cell clone B7 is expressing GFP as observed live under a fluorescent microscope. The background clone D5 (Puro ${ }^{\mathrm{R}} \mathrm{G} 418^{\mathrm{R}}$ ) that has a random integration does not have GFP expressed. 
Author contributions

Kristina Williams: Conception and design, collection and assembly of data, data analysis and interpretation, manuscript writing. Xiaoyun Zhao: Collection and assembly of data, manuscript writing. Wallace Chick: Conception and design, financial support, collection and assembly of data, data analysis and interpretation, manuscript writing, final approval of manuscript.

\section{Competing interests}

No competing interests were disclosed.
Grant information

This work is supported by the National institute of Health (NIH), Rocky Mountain Neurological Disorders core grant P30 NS048154. This paper is subject to the NIH Public Access Policy.

The funders had no role in study design, data collection and analysis, decision to publish, or preparation of the manuscript.

Acknowledgements

We would like to thank Ms Irene Choi for her proofreading of the manuscript.

\section{References}

1. Shinohara ET, Kaminski JM, Segal DJ, et al.: Active integration: new strategies for transgenesis. Transgenic Res. 2007; 16(3): 333-9.

PubMed Abstract | Publisher Full Text

2. Araki K, Araki M, Yamamura K: Site-directed integration of the cre gene mediated by Cre recombinase using a combination of mutant lox sites. Nucleic Acids Res. 2002; 30(19): e103.

PubMed Abstract | Publisher Full Text | Free Full Text

3. Chick WS, Mentzer SE, Carpenter DA, et al.: X-ray-induced deletion complexes in embryonic stem cells on mouse chromosome 15. Mamm Genome. 2005; 16(9): 661-671.

PubMed Abstract | Publisher Full Text

4. Kwan KM: Conditional alleles in mice: Practical considerations for tissuespecific knockouts. Genesis. 2002; 32: 49-62. PubMed Abstract | Publisher Full Text
5. Hayashi S, McMahon AP: Efficient recombination in diverse tissues by a tamoxifen-inducible form of Cre: a tool for temporally regulated gene activation/inactivation in the mouse. Dev Biol. 2002; 244(2): 305-18. PubMed Abstract | Publisher Full Text

6. Matsuda T, Cepko CL: Controlled expression of transgenes introduced by in vivo electroporation. Proc Natl Acad Sci U S A. 2007; 104(3): 1027-32.

PubMed Abstract | Publisher Full Text | Free Full Text

7. Ramírez-Solis R, Rivera-Pérez J, Wallace JD, et al.: Genomic DNA microextraction: a method to screen numerous samples. Anal Biochem. 1992; 201(2): 331-335.

PubMed Abstract | Publisher Full Text

8. Chick WS, Drechsel DA, Hammond W, et al:: Transmission of mutant phenotypes from ES cells to adult mice. Mamm Genome. 2009; 20: 734-740. PubMed Abstract | Publisher Full Text | Free Full Text 


\section{Open Peer Review}

\section{Current Peer Review Status: ? $\mathrm{X} \times$}

\section{Version 1}

Reviewer Report 05 November 2013

https://doi.org/10.5256/f1000research.1783.r2313

(C) 2013 Haenebalcke L. This is an open access peer review report distributed under the terms of the Creative Commons Attribution License, which permits unrestricted use, distribution, and reproduction in any medium, provided the original work is properly cited.

\section{Lieven Haenebalcke}

Department for Molecular Biomedical Research, Ghent University, Ghent, Belgium

The authors describe a method to generate transgenic mouse embryonic stem cells by knocking in a constitutive or conditional expression vector to the ROSA26 locus by a recombinase-mediated cassette exchange (RMCE) approach. Although the authors already state in their abstract that this can be a simple and efficient procedure to generate transgenic mice in many laboratories, this is not proven by this article. Additionally and as already mentioned by the other two reviewers, this story clearly lacks novelty and does not refer to the most recent publications describing similar and even more efficient ROSA26-based RMCE technologies.

\section{Major comments:}

1. The introduction is not up to date as it does not refer to the most recent reports on RMCEbased transgenic technologies. More importantly, it does not describe how this study is of added value to the field or how it distinguishes itself from these other reports (see reference list reviewer Juergen Bode).

2. It is not clear why one particular RMCE-compatible ES cell clone was chosen over the others. It would be nice to see Southern blot confirmation of correct and single transgene integration, karyotyping data, pluripotency analysis and ability of these ES cells to establish transgenic animals after in vitro manipulation.

3. A more schematic overview of the constructs, RMCE-strategy and expression mechanism should be given to enhance the clarity of this method for less-experienced readers, e.g. include the splice acceptor which is required to obtain endogenous ROSA26 promoterbased expression of the RMCE-inserted transgene.

4. As already mentioned by the other two reviewers, Figure $2 \mathrm{C}$ is not clear at all. Additionally, the PCR strategy should also be backed-up by Southern blot analysis to give an idea on possible secondary, random integrations. Separate targetings should be performed to get a real, statistically significant estimate on the efficiency of this RMCE approach.

5. Figure 2D: Did all correctly targeted ES cell clones express the same levels of GFP and was this expression equal in all cells of one particular clone? In other words, how robust and wide spread is this ROSA26-based system? 
6. No experimental data is given for the pFLSL-WF3 conditional vector system (Cre/loxP). Was this vector tested? Please include data. If it did not work, the authors cannot state they have also developed a conditional system

7. Summary: the authors state this is a very efficient system for gene knock-in at the ROSA26 locus, both constitutive and conditional. However, this approach still requires traditional cloning of the CDNA of interest into the targeting vectors and the picking and screening of approximately 100 individual ES cell clones per construct. It is not clear to me how this method is superior to a very similar but previously published ROSA26-based approach, which even makes use of homologous recombination instead of RMCE (Nyabi et al. Efficient mouse transgenesis using Gateway-compatible ROSA26 locus targeting vectors and F1 hybrid ES cells Nucleic Acids Research; 37(7), 2009), especially because no data is provided to prove that the method described here can generate transgenic animals.

In general, I am convinced that there are other, more reliable, tested and efficient systems available to generate such ROSA26-based transgenic ES cells and animals than the RMCE approach described here.

Competing Interests: No competing interests were disclosed.

\section{I confirm that I have read this submission and believe that I have an appropriate level of expertise to state that I do not consider it to be of an acceptable scientific standard, for reasons outlined above.}

Reviewer Report 03 October 2013

https://doi.org/10.5256/f1000research.1783.r1850

(C) 2013 Bode J. This is an open access peer review report distributed under the terms of the Creative Commons Attribution License, which permits unrestricted use, distribution, and reproduction in any medium, provided the original work is properly cited.

\section{Juergen Bode}

Experimental Hematology, Hannover Medical School, Hannover, Germany

Over all, the method described in this article does not seem to provide any benefits over previously published methods. Several details of the procedure are hard to understand since they are not clearly described either in the text or the figure legends. We also have concerns that the quality of the figures is below the standard we would expect.

Specifically we have the following comments/queries:

1. Why was the targeting construct inserted in the opposite orientation? Was this perhaps to circumvent the promoter effects from the ROSA26 intrinsic promoter? This is not clearly stated in the article and should be explained.

2. Why was Flpe been used and not Flpo (which has been known to be superior for several years)?

3. Fig. 1b: The text is hard to follow. Which transgenes were cloned into the constructs? It would be helpful if the authors could provide a schema depicting the cloning strategy. 
4. Fig. 2 is of poor quality overall. 2C: This PCR picture is inacceptable (as there are no annotations of size). Something has been written on the gel picture but it is hard to read as it is far too small.

5. The ES cells used for RMCE were not characterized with regard to pluripotency and checked for karyotypic aberrations. Including these points in the article would be useful.

6. We had major problems understanding the loxP site insertions in the vector. The positions are not clearly described in the text. Why is the stop site $4 \times \mathrm{pA}$ ?

7. The manuscript does not mention that the promoter driving the transgenes is the endogenous one. This should be added and explained.

8. Our most serious concern is that very similar approaches (ROSA26 targeted by Flp-RMCE using $\mathrm{F}$ and $\mathrm{F} 3$ sites) have already been published, at least three times ${ }^{1,2,3}$. We would have expected these papers to have been cited in the article and any advantages in the authors' method to be discussed in relation to these previously described approaches.

\section{References}

1. Seibler J, Küter-Luks B, Kern H, et al.: Single copy shRNA configuration for ubiquitous gene knockdown in mice.Nucleic Acids Res. 2005; 9 (33). PubMed Abstract | Free Full Text | Publisher Full Text

2. Tchorz JS, Suply T, Ksiazek I, et al.: A Modified RMCE-Compatible Rosa26 Locus for the Expression of Transgenes from Exogenous Promoters. PLos One. 2012; 7. PubMed Abstract | Free Full Text | Publisher Full Text

3. Haenebalcke L, Goossens S, Naessens M, et al.: Efficient ROSA26-Based conditional and/or Inducible Transgenesis Using RMCE-Compatible F1 Hybrid Mouse Embryonic Stem Cells.Stem Cell Rev.2013. PubMed Abstract | Publisher Full Text

Competing Interests: No competing interests were disclosed.

I confirm that I have read this submission and believe that I have an appropriate level of expertise to state that I do not consider it to be of an acceptable scientific standard, for reasons outlined above.

Reviewer Report 08 August 2013

https://doi.org/10.5256/f1000research.1783.r1263

(C) 2013 Clancy J. This is an open access peer review report distributed under the terms of the Creative Commons Attribution License, which permits unrestricted use, distribution, and reproduction in any medium, provided the original work is properly cited.

\section{Jennifer Clancy}

College of Medicine, The Australian National University, ACT, Australia

This article describes a method to insert a recombination cassette specifically into the ROSA26 allele. However I find it hard to establish how novel this method is and how much better it is then existing protocols from the work outlined here. Also, the results did not summarise the efficiency 
and specificity of this system well (which would have been nice to see in the figures) and I was unclear as to whether the pCAG-Flpe plasmid was a control or a comparison plasmid (and there were unclear results from this work). Additionally, only using examples to show the outcomes instead of statistics does not demonstrate how good the method is, only some of the potential outcomes. Also, what is the FRT-neo-F3 cassette mentioned in the last line?

I am not an expert in transgenic mouse generation, but I do know that the ROSA locus has been used for some time. What is the essential advancement with this method?

Also, please label panel $2 \mathrm{C}$ so meaning can be derived from it.

I think some work needs to be done to enhance the clarity of the objectives, outcomes and any novelty in this article. Also, perhaps some better schematics of the various cassettes mentioned in the text would help the reader follow what they are being used for.

Competing Interests: No competing interests were disclosed.

I confirm that I have read this submission and believe that I have an appropriate level of expertise to confirm that it is of an acceptable scientific standard, however I have significant reservations, as outlined above.

The benefits of publishing with F1000Research:

- Your article is published within days, with no editorial bias

- You can publish traditional articles, null/negative results, case reports, data notes and more

- The peer review process is transparent and collaborative

- Your article is indexed in PubMed after passing peer review

- Dedicated customer support at every stage

For pre-submission enquiries, contact research@f1000.com

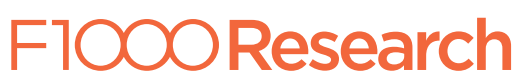

